\title{
A nomeação de pessoas em diferentes comunidades surdas
}

\author{
Gabriele Cristine Rech ${ }^{*}$ \\ Fabíola Sucucupira Ferreira Sell ${ }^{* *}$ \\ Márcia Sipavicius Seide ${ }^{* * *}$
}

\begin{abstract}
Resumo: Este artigo apresenta uma análise de revisão de literatura de pesquisas sobre o processo de nomeação de pessoas em diferentes comunidades surdas para verificar se essas pesquisas estão inseridas no campo da Antroponomástica com base numa seleção de artigos publicados em português e em inglês (1989-2018), utilizando palavras-chave em sites de busca. Descreve-se a nomeação de pessoas nas línguas de sinais de comunidades de surdos em alguns países, apresenta-se um panorama histórico dos estudos onomásticos nas línguas de sinais e observam-se aspectos culturais na nomeação, revelando atitudes, posturas sociais dos nomeadores e crenças, profissões e regiões de origem dos nomeados.
\end{abstract}

Palavras-chave: Língua de Sinais. Sinal de Nome. Antroponomástica.

Abstract: We analyze reviews of literature in researches focusing on the process of naming people in deaf communities from some countries. It is verified whether these researches are inserted in the Anthroponomastics field. A selection of articles in Portuguese and English (1990 - 2018) was made, using keywords in search engines. We describe people's naming in sign languages in these communities, seeking to present a historical overview of onomastic studies in those sign languages. As results, cultural aspects are observed in naming, revealing social attitudes of the name's givers, as well as beliefs, professions, regions of origin, of the people named.

Keywords: Sign Language. Name Sign. Anthroponomastics.

Resumen: Se presenta una revisión de literatura de investigaciones sobre el proceso de nombramiento de personas en comunidades sordas de algunos países. El objetivo es verificar si estas investigaciones están insertadas en el campo de la Antroponomática, basada en una selección de artículos publicados en portugués e inglés (1990 - 2018), mediante el uso de palabras clave en los motores de búsqueda. Se describen el nombramiento de personas en las lenguas de signos de comunidades sordas abarcadas. Se presentan aspectos culturales en el nombramiento,

\footnotetext{
* Doutoranda do Programa de Pós-Graduação em Letras da Universidade Estadual o Oeste do Paraná. Professora de Libras da Universidade Estadual de Mato Grosso do Sul. http://orcid.org/oooo-0003-2470-3416

** Professora de Libras e de Língua Portuguesa. Membro permanente do Programa de Pós-Graduação em Ensino de Ciências, Matemática e Tecnologias da Universidade do Estado de Santa Catarina (UDESC, Joinville). http://orcid.org/o0oo-0002-2315-7073

${ }_{* * *}$ Professora Associada da Universidade Estadual do Oeste do Paraná. Docente do Curso de Letras da UNIOESTE, campus de Marechal Cândido Rondon. http://orcid.org/oooo-0003-2859-1749
}

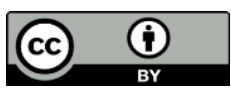


actitudes y posturas sociales de los nombradores además de creencias, profesiones, regiones de origen de los nombrados.

Palabras claves: Lengua de signos. Señal de nombre. Antroponomástica.

\section{Introdução}

O hábito de dar nomes às pessoas reflete aspectos culturais de uma sociedade. Um nome próprio pode registrar atitudes e posturas sociais de um determinado grupo, bem como crenças, profissões, regiões de origem, dentre outros aspectos (CARVALINHOS, 2007). Day e Sutton-Spence (2010, p. 23), por sua vez, afirmam que compreender as práticas de nomeação pode levar ao entendimento das crenças culturais de uma comunidade, suas práticas linguísticas e estruturas sociais com inclusão das relações familiares. Dentro dos estudos linguísticos há uma área voltada especificamente sobre os nomes próprios, a Onomástica cujas características principais são apresentadas na primeira seção deste artigo.

A forma como os nomes são atribuídos e utilizados nas culturas ocidentais ou ocidentalizadas, vai depender do modo como cada sociedade se organiza cultural e linguisticamente; no entanto, algumas características são comuns, como: o processo de escolha do nome, a singularidade deste nome, bem como a relação entre o nome e a identidade pessoal do sujeito nomeado (PAALES, 2010, p. 319).

Neste contexto, esse trabalho tem por objetivo apresentar uma revisão bibliográfica de pesquisas que discutem fatores sociais e culturais na forma de nomear em diferentes comunidades surdas, bem como verificar se essas pesquisas estão inseridas dentro do campo da Onomástica e propor com base na revisão de literatura realizada, algumas perspectivas de pesquisa. Para a coleta dos artigos contemplados nesta revisão, foi feita uma busca na internet utilizando-se palavras-chave em sites de busca na internet e, levando-se em conta artigos publicados em português e em inglês. Essa busca foi realizada a partir dos seguintes descritores: signs names; onomastics; anthroponyms; sinais de nomes na Libras; Libras e onomástica, em setembro de 2018. Como resultados dessa busca, foram localizados trabalhos nas línguas de sinais americana, britânica, sueca, grega, japonesa, francesa, estoniana, brasileira e turca. A este conjunto de artigos foi acrescentada uma pesquisa publicada posteriormente (BARROS, 2018). Para este 
trabalho optamos por excluir os artigos que tratavam das questões fonológicas dos sinais de nome, os artigos que não estavam em língua inglesa ou portuguesa e dissertações. Por estes critérios de seleção, contemplamos o artigo de Supalla (1990)ㄹ, reconhecido como um dos primeiros trabalhos sobre os sinais de nome da Língua de Sinais Americana (doravante ASL), e artigos que versam sobre os sinais de nome de comunidades surdas de países com tradições linguísticas e culturais bem diferentes, a saber: britânica, chinesa, grega, sueca e brasileiras. Ressalte-se que uma das dificuldades encontradas na busca está no fato de que muitos estudos não relacionam a pesquisa com a área da Onomástica.

Este artigo está organizado da seguinte maneira: na primeira seção, situa-se a área de estudos com uma breve cronologia da onomástica que contextualiza esta área do conhecimento. Na seção seguinte, busca-se localizar os estudos antroponomásticos das línguas de sinais dentro desse panorama, na próxima seção, são apresentados os estudos encontrados nas línguas de sinais citadas anteriormente e, por fim, na seção final deste artigo, é feita uma avaliação das investigações relatadas de acordo com a Antroponomástica e são apresentadas algumas perspectivas inovadoras de pesquisa.

\section{Os estudos onomásticos}

Dentre as várias vertentes que a lexicologia se propõe a estudar, a Onomástica é a ciência que estuda os nomes próprios dividida em duas áreas: Toponomástica e Antroponomástica. A primeira trata dos nomes dos lugares e a segunda dos nomes individuais de pessoas. Esta ciência dialoga com outras áreas do conhecimento, como a História, a Geografia, a Arqueologia, dentre outras, mostrando a riqueza, a importância e a interdisciplinaridade desta área (SEABRA; ISQUERDO, 2018).

Os estudos onomásticos se ocupam do estudo da função simbólica e representativa que os signos amparam, pois vão além de perceber a função nomenclatória dos nomes próprios. Eles remetem ao passado, uma vez que nomes de

\footnotetext{
${ }^{1} \mathrm{O}$ trabalho de Shun-chiu e Jingxian (1989), embora anterior, apresenta apenas um estudo de caso, sem trazer uma categorização dos sinais de nome, como o faz Supalla, o qual é reconhecido como o primeiro pesquisador a categorizar os tipos de sinais de nome (1990).
} 
pessoas e nomes de lugares são "produto de um sistema de denominação que reflete o modo de viver de uma cultura e a mesma maneira desta representar seus valores" (SEABRA; ISQUERDO, 2018, p. 994).

Seabra e Isquerdo (2018) apontam Dauzat (1951) como aquele que concebeu a Onomástica como ciência. De acordo com esse linguista, a Onomástica é a união de Antroponímia (ciência que estuda o nome das pessoas ou antropônimo) e Toponímia (ciência que estuda o nome dos lugares ou topônimos). Porém, o Conselho Internacional de Ciências Onomásticas (ICOS), em 2011, propôs uma diferenciação terminológica: enquanto antroponomástica e toponomástica são as disciplinas que estudam os antropônimos e topônimos, respectivamente; antroponímia e toponímia representam o conjunto dos nomes próprios e de lugares, respectivamente (SEIDE, 2016, p. 1147). Para fins deste trabalho, adotamos a terminologia sugerida pelo ICOS.

O estudo do nome próprio pode ser realizado através de diferentes abordagens com diversas finalidades. É possível estudar a etimologia dos nomes, as motivações das atribuições de nomes, a relação do nome com a cultura, dentre outras. A abordagem que nos interessa, neste estudo, chama-se sócio antroponomástica, que pode ser caracterizada como uma subdisciplina onomástica que estuda a interação entre antropônimos ou nomes próprios, e a comunidade de fala que os emprega (BRAMWELL, 2011 apud LÓPEZ FRANCO, 2014).

Frai (2016), de uma maneira mais abrangente, conceitua a Sócio-Onomástica como uma abordagem que visa "o estudo das motivações dos antropônimos considerando o contexto social, cultural em que o designador atribui o nome" (FRAI, 2016, p. 94) $)^{2}$.

No que concerne os estudos toponímicos, segundo Dick (1992), foi através de Auguste Longnon que a disciplina Sócio-onomática se sistematiza na Europa, em 1878. Neste sentido, é possível notar que esta área não é tão recente, apesar de não ser muito conhecida no meio acadêmico brasileiro. Em 1922, Albert Dauzat retoma os estudos que

\footnotetext{
${ }^{2} \mathrm{~A}$ autora sustenta sua afirmação através dos estudos de Guérios (1981), o qual aponta que além do aspecto etimológico, os nomes próprios podem ser estudados "sob o aspecto social ou psicossocial, ou da sua escolha ou das razões porque são ou foram sempre empregados (...)" (GUÉRIOS, 1981, p. 16 apud FRAI, 2016, p. 94).
} 
foram interrompidos com a morte de Longnon. O pesquisador, em 1938, organizou o I Congresso Internacional de Toponímia e Antroponímia, onde vinte e um países foram representados com várias resoluções voltadas para a consolidação dos estudos Onomásticos, bem como sistematização de normas de pesquisas a serem seguida pelos pesquisadores (Dick, 1992, p. 2). Segundo Silva e Moraes (2015), os estudos toponímicos se espalharam primeiro pela Europa e, após a realização de alguns congressos, bem como a abertura de centros de pesquisas onomásticas pelo mundo, ela vem se consolidando em outros países. Nas Américas, o destaque é para os estudos realizados nos Estados Unidos e no Canadá (SILVA; MORAES, 2015).

No Brasil, os estudos realizados inicialmente foram voltados para as línguas indígenas brasileiras. Uma das maiores referências no Brasil é a professora Maria Vicentina de Paula do Amaral Dick, em cuja tese de doutorado estudou a toponímia brasileira e criou um sistema de taxonomia voltado para as pesquisas de nomes de lugares no Brasil (SEABRA, ISQUERDO, 2018).

Em relação aos estudos antroponomásticos, foco deste artigo, Dick (1992) aponta alguns trabalhos que marcaram a área e que nos auxiliam a perceber quando mais ou menos a área começa a ser estudada, uma vez que, segundo a própria autora, os estudos em relação aos topônimos se tornaram uma área mais autônoma do que os estudos antroponomásticos. A pesquisadora aponta Leite de Vasconcelos (1887) como quem utilizou o termo "antroponímia" pela primeira vez e que mais tarde publica Antroponímia Portuguesa (1928). Destaca também os trabalhos de Albert Dauzat - Les noms de personnes (1934) e Les noms de famille de France (1945). No Brasil, um dos estudiosos pioneiros é Rosário Farâni Monsur Guerios, que, em 1973, publica o Dicionário Etimológico de nomes e sobrenomes, em cuja introdução apresenta uma pesquisa sobre aspectos linguísticos e psicossociais da antroponomástica, bem como sua aplicação ao Brasil.

\section{Onomástica e línguas de sinais}


A comunidade surda, através das línguas de sinais, também nomeia pessoas e lugares, conforme descrevemos mais adiante. Para identificar as pessoas, são utilizados sinais de nomes, um antropônimo organizado da mesma forma que as pessoas surdas organizam a língua e percebem o mundo: através do canal espaço-visual. Este artigo se propõe a fazer uma revisão bibliográfica de artigos que descrevem a nomeação de pessoas nas línguas de sinais em algumas comunidades de surdos de alguns países, verificando traços em comum e diferenças.

Nas comunidades surdas, é comum atribuir um sinal para pessoas que fazem parte da comunidade surda, de forma a reconhecê-las como membros ou a identificar aquelas que não fazem parte desta comunidade, mas precisam ser identificadas por razões diversas. Pesquisadores chamam esse signo de sign name (DAY e SUTTONSPENCE, 2010; SUPALLA, 1990; MINDESS, 1990) ou personal name signs (PAALES, 2010) que traduzimos aqui como "sinais de nomes".

Para as pessoas surdas em especial, um sinal de nome, além de marcar a sua entrada na comunidade surda, simboliza linguística e culturalmente um vínculo deste sujeito com o novo grupo ao qual pertence. Essa interação é essencial, pois, muitas vezes, os surdos apresentam uma interação maior com seus pares do que com sua família de origem, salvo surdos filhos de pais surdos (TOPRAKSOY, 2015).

Da mesma forma que acontece com as crianças ouvintes, as crianças surdas também têm um nome oficial, aquele que consta nos documentos oficiais e, em grande parte das culturas, de modo geral, é dado no nascimento pelos próprios pais. No entanto, segundo pesquisadores da Língua de Sinais da Nova Zelândia, esses nomes não são acessíveis às crianças surdas, uma vez que é difícil ensinar seu significado social e linguístico a elas, pois usam da modalidade gestual para a interação, não podendo ouvir a pronúncia de seus nomes (McKEE \& McKEE 2000, p. 9).

\section{Estudos sobre sinais de nomes em diferentes línguas de sinais}

O pesquisador surdo Samuell J. Supalla publicou, em 1990, o artigo denominado The Arbitrary Name Sign System in American Sign Language (O Sistema de Sinal de 
Nome Arbitrário na Língua Americana de Sinais), em que aponta diferenças entre os sinais de nomes descritivos e sinais de nomes arbitrários e discute detalhes das propriedades linguísticas e fatores sociais do sistema arbitrário. Barros (2018) esclarece que os nomes por ele classificados como arbitrários não são nomes não motivados, mas sim nomes não descritivos (BARROS, 2018, p. 10).

Segundo Supalla (1990), os sinais de nomes descritivos são baseados em características ou aparência da pessoa nomeada, sem relação com o seu nome na língua falada; esses seguem as regras de formação de sinais da Língua de Sinais Americana (American Sign Language - ASL), que são aplicáveis ao movimento, ponto de articulação e configuração de mão, em que esta última, segundo o autor, se comporta como um classificador ${ }^{3}$.

Conforme o autor, os sinais de nomes arbitrários simplesmente nomeiam, sem um outro significado, utilizando a configuração de mão para representar a letra inicial do nome em inglês - que pode ser o primeiro nome, o sobrenome ou o apelido - ou duas configurações de mão para denotar o primeiro e o segundo nome, ou o primeiro e o último nome na língua inglesa. Ele esclarece que as configurações de mão utilizadas para representar esses sinais são exclusivamente as do alfabeto manual e não se comportam como classificadores.

Não há referências no artigo sobre os estudos onomásticos; além disso, as informações a respeito da metodologia adotada no artigo não estão muito claras, apenas há uma menção referente a uma pesquisa informal realizada com sete surdos nativos e um quase nativo (expressão que o autor não elucida), todos matriculados em diferentes escolas residenciais para surdos nos Estados Unidos. Segundo o autor, cada surdo confirmou a sua intuição: o sistema arbitrário de sinais de nome é bastante uniforme na comunidade surda americana. Esse sistema é regido por regras próprias para formar os sinais de nome e está relacionado com a fonologia da ASL.

Entretanto, para fins desta investigação, atentemo-nos ao viés social da atribuição de sinais de nomes na ASL. Supalla (1990) afirma que a atribuição de um sinal de nome

\footnotetext{
3Segundo o autor, um sinal classificador é "um tipo especial de pronome usado na língua para se referir a tamanhos ou formas de objetos a pessoas, veículos, etc” (T. SUPALLA, 1985 apud SUPALLA, 1990, p. 101. Tradução nossa).
} 
descritivo ou arbitrário está fortemente ligada à identidade dos pais, ou seja, se são ouvintes ou surdos. No caso das crianças surdas filhas de pais ouvintes, seus sinais de nome são dados geralmente na escola e, na grande maioria das vezes, recebem um sinal de nome descritivo.

O autor afirma ainda que, em suas observações como membro nativo da comunidade surda, constata que praticamente todas as crianças surdas filhas de pais surdos têm um sinal de nome arbitrário e, neste sentido, o pesquisador acredita que este é o sistema nativo da comunidade surda em nomear, mas deixa claro que ambos os sistemas possuem o mesmo status, uma vez que se propõem a ser um sinal de nome primário para a criança surda. Na última seção deste artigo, se discute com mais profundidade se a função dos nomes de sinais é secundária ou primária, de acordo com os paradigmas em vigor na Antroponomástica.

O artigo British Sign Name Customs (2010) - Os Costumes Britânico dos Sinais de Nome - escrito pelas pesquisadoras Rachel Sutton-Spence e Linda Day, parte do princípio de que os nomes de sinais revelam valores dos usuários da Língua Britânica de Sinal (British Sign Language - BSL), bem como características do processo de formação de sinais desta língua. A partir desses pressupostos, as autoras buscam estudar mais especificamente o processo de atribuição de sinais de nomes realizados por pais surdos a seus filhos surdos. As autoras também não situam seus estudos no campo da Onomástica.

Para coletar dados para desenvolver a pesquisa, as autoras informam que a pesquisadora surda enviou um e-mail explicando o projeto para setenta e seis surdos para participar da pesquisa, e solicitando um encontro presencial aos que quiseram participar da pesquisa. As entrevistas foram todas filmadas, feitas na Língua de Sinais Britânica. Os dados foram analisados levando-se em conta três áreas específicas: idade da aquisição dos sinais de nomes, o número de sinais de nomes de um determinado membro e os tipos de sinais de nome. Dos setenta e seis surdos entrevistados, 44\% (34 informantes) são filhos surdos de pais surdos, e os demais são filhos surdos de pais ouvintes. Esses participantes entraram na escola de surdos até os 5 anos de idade e, na época da entrevista, tinham entre 18 e 95 anos, representando quase um século, uma vez que abrange as décadas de 1910 a 1990. 
A pesquisa constatou que as crianças surdas, quer sejam filhas de pais surdos ou ouvintes, na sua grande maioria, não recebem seus sinais de nome no momento do nascimento. Segundo as autoras, surdos filhos de pais surdos tendem a usar a forma digitalizada do nome em inglês, conforme ocorre na comunidade surda de língua de sinais americana (SUPALLA, 1992), na comunidade surda do Quebec (DESROSIERS; DUBUISSON, 1994) e na comunidade surda da Nova Zelândia (MCKEE; MCKEE, 2000). Os dados revelaram que $24 \%$ desses surdos continuaram com um sinal de nome utilizando datilologia. Já os filhos surdos de pais ouvintes geralmente recebem seus sinais de nome ao entrar na escola, quando começam a ter contato com seus pares surdos, pois é bem improvável que pais ouvintes atribuam um sinal de nome aos filhos surdos. Apenas $5 \%$ dessas crianças tiveram seus sinais de nomes baseados na datilologia.

As autoras discutem o que chamam de paradoxo da atribuição de nomes feita pelos pais surdos aos filhos surdos, utilizando a datilologia correspondente aos nomes na língua oral versus o sinal de nome como símbolo de pertencimento ao grupo. Segundo as pesquisadoras, quando uma pessoa não faz parte da comunidade surda, mas precisa ser referenciada, é através do uso do alfabeto manual que elas são identificadas. Neste sentido, o uso desse recurso indica um não pertencimento à comunidade surda. Mas então, que justificativa existe para a nomeação de filhos surdos por pais surdos usando a datilologia do nome correspondente na língua oral?

Algumas hipóteses são apresentadas no mesmo artigo. A primeira diz respeito à relação próxima entre a BSL e a língua inglesa, mostrando o bilinguismo dos surdos britânicos onde o uso do alfabeto manual não demonstra rejeição à sinalização. Outra questão diz respeito ao pertencimento da criança surda, filha de pais surdos, à comunidade, uma vez que estas não precisariam de sinais de nomes descritivos para garantir sua inserção no grupo. Outra questão é que os pais surdos já precisam escolher um nome na língua oral para esta criança e isso já faz parte da identidade do filho. Outra hipótese ainda é que um nome de sinal serve apenas para identificar e não é usado vocativamente. Usar o nome não faz parte do processo de ligação de pais e filho, esse estreitamento acontece mais pelo olhar, então a escolha de um sinal de nome usando a datilologia não mostra distância entre eles e seu filho. 
No que diz respeito à quantidade de sinais nomes que um mesmo surdo pode ter, os dados do artigo demonstram que além dos $24 \%$ dos surdos, filhos de pais surdos, que possuem sinais de nome utilizando apenas a datilologia, 61\% possuem apenas um sinal de nome, $15 \%$ dois sinais de nome e nenhum entrevistado apresentou mais que dois sinais de nome. Em relação às crianças surdas, filhas de pais ouvintes, 5\% apenas usam a datilologia para seus sinais de nome, $70 \%$ possuem um sinal de nome, $23 \%$ dois sinais de nome e $2 \%$ apresentaram mais que dois sinais de nome.

A última questão analisada diz respeito às motivações das atribuições dos sinais de nomes. Cientes de que não possuem dados estatisticamente significativos sobre as porcentagens das categorias, as autoras identificaram aparência e maneirismos como as mais comuns, tanto para filhos surdos de pais surdos como para filhos surdos de pais ouvintes. Elas sugerem como possibilidade de justificativa para estas categorias, o fato de estas crianças receberem seus sinais de nome na escola, período em que já desenvolveram aparências e personalidade. Esta pesquisa traz informações importantes sobre o processo de nomeação na sociedade surda as quais são avaliadas, na última seção, segundo os paradigmas e pressupostos da Antroponomástica.

Börstell (2017), em seu artigo Types and Trends of Name Signs in the Swedish Sign Language Comunity - Tipos e Tendências de sinais de nome na Comunidade de Língua de Sinais Sueca -, analisa os sinais de nomes da Suécia a partir de algumas propriedades sociolinguísticas da nomeação de pessoas, como por exemplo: idade, sexo, identidade da pessoa que recebe e atribui um sinal de nome (ouvintes ou surdos) e a relação entre o nomeado e quem o nomeia (família ou amigo). Outra finalidade apresentada no artigo é demonstrar possíveis mudanças no costume de nomear ao longo do tempo. Nas palavras-chave do artigo, aparecem os termos "onomástica" e "antropônimos", entretanto, no decorrer do artigo, não há nenhuma sessão que desenvolva explicitamente essa temática. Porém, do ponto de vista metodológico, sua pesquisa se enquadra no paradigma sócio onomástico de pesquisa.

A metodologia empregada pelo autor é de caráter qualitativo, realizada através de questionário on-line, que ficou disponível pelo período de 5 a 28 de janeiro de 2017 . Os informantes foram contatados em grupos das redes sociais, principalmente através do Facebook. No total, foram coletados 737 sinais de nomes, que não necessariamente 
correspondem a 737 indivíduos, uma vez que uma pessoa pode ter mais de um sinal. $\mathrm{O}$ questionário era composto por quatro etapas, totalizando 12 questões. A primeira etapa diz respeito à apresentação da pesquisa. A segunda etapa foi destinada a permitir que o entrevistado categorizasse seu sinal de nome a partir de tipos apresentados e demonstrar se sua percepção do seu sinal de nome era positiva ou negativa. A terceira etapa consistia na percepção do informante do subtipo que o seu sinal de nome pertencia, interligada à segunda etapa e, na quarta etapa, o informante preenchia informações próprias e a identidade de quem atribuiu o sinal: surdo, ouvinte ou CODA (pessoa ouvinte filha ou filho de pais surdos).

Para organizar os tipos e os subtipos apresentados nas etapas dois e quatro, Börstell (2017) baseou-se nos estudos de Hedberg (1989; 1994 apud BÖRSTELL, 2017, p.10), que coletou, na Suécia, aproximadamente 3.114 sinais de nomes no final da década de 1980. Börstell (2017) categorizou esses signos em cinco tipos: motivados pelo portador (aparência), pessoa (caráter ou ação do portador do sinal de nome), nome (relacionado ao nome da comunidade de língua falada do portador), antecedentes (referente a algum aspecto histórico do nomeado) e outros (quando não se enquadram em nenhuma categoria anterior).

Ademais, essas tipologias basilares são ainda subdivididas. A “aparência” é composta por cinco subtipos, por exemplo: cabelo; fisionomia, vestimenta. Há ainda os recursos metáfora, quando se utiliza de outro sinal para melhor explicar a característica da pessoa (o emprego do sinal "farol" para se referir à altura) e outros, quando nenhum dos itens mencionados se aplica. Os sinais do tipo "pessoa" e "nome” são organizados em sete e oito subtipos, respectivamente. Os primeiros abarcam elementos da personalidade, profissão, passatempo ou mesmo um sinal associado ao indivíduo por causa do uso frequente. Os segundos elencam nomenclaturas que vão desde a apresentação de uma letra até o nome completo do indivíduo a partir do emprego do alfabeto manual. Já a categoria “antecedentes" conta com três subtipos. Estes dizem respeito ao país ou à cidade de origem do portador, como, também, a algo herdado, isto é, se o nome for herança de um parente. Por fim, a tipologia “outros" não contém nenhum subtipo, mas reúne sinais que não se enquadram em nenhuma das categorizações acima mencionadas (BÖRSTELL, 2017, p. 15). 
Os dados foram analisados estatisticamente, e apresentam resultados que, segundo Börstell (2017), são análogos a outras comunidades de línguas de sinais, como o fato de os sinais descritivos serem mais comuns e a tendência de as crianças surdas filhas de pais surdos receberem seus sinais mais precocemente que as crianças surdas filhas de pais ouvintes, que geralmente recebem seus sinais de nome na época escolar. Outro resultado apresentado é a existência de uma diferença na forma de nomear homens e mulheres, em que os primeiros apresentaram mais sinais de nomes relacionados à personalidade e comportamento e as últimas relacionados à aparência física. Entretanto, a pesquisa também mostrou que a nomeação das mulheres vem mudando ao longo do tempo, aparecendo nos últimos anos mais sinais de comportamento e personalidade sendo atribuídos às mulheres.

Outro dado importante diz respeito à identidade do name giver - traduzido por nós por nomeadores -, ou seja, aqueles que atribuem os sinais de nomes. Segundo os autores, foi possível observar que os nomeadores surdos, proporcionalmente, atribuíram mais sinais relacionados à aparência. $\mathrm{O}$ autor levanta a hipótese de que essa questão pode estar relacionada à questão de o nomeador estar focado em sua própria língua.

A respeito dos nomes de sinais gregos, Kourbetis e Hoffmeister (2002), publicaram o artigo Name Signs in Greek Sign Language (Sinais de Nomes na Língua de Sinais Grega), em que buscaram conhecer as regras que delineiam o processo de nomear pessoas na Língua de Sinais Grega (Greek Sign Language - GSL). Para tanto, os pesquisadores entrevistaram duzentas pessoas (100 surdas e 100 ouvintes que conheciam a língua de sinais), utilizando um questionário elaborado anteriormente contendo 10 perguntas que tratavam de dados pessoais como: a forma do sinal de nome, os sentimentos em relação a este sinal de nome e a idade que adquiriu a língua de sinais. Além de responder ao questionário, 14 surdos e 6 ouvintes foram entrevistados com o objetivo de obter dados adicionais, tais como informações de sinais de nomes de pessoas famosas, uso de apelidos e nomes usados para provocar ou insultar alguém entre os surdos, formas de diferenciar pessoas com o mesmo sinal, dentre outras. Esta é a única pesquisa que menciona a categoria dos apelidos, noção retomada na última seção deste artigo. 
Os autores utilizaram as duas categorias sugeridas por Supalla (1992): descritivos e arbitrários. Os dados mostraram que 92\% dos entrevistados relataram ter sinais de nomes descritivos, revelando, segundo os autores, que mesmo metade dos informantes sendo ouvintes, não há uma influência da língua grega oral na formação desses sinais. Dentre esses sinais descritivos, $55 \%$ eram sinais relativos à aparência física e $21 \%$ referentes à personalidade.

A respeito da origem dos sinais de nome na Língua de Sinais Grega, foi observado que as crianças surdas, filhas de pais ouvintes, recebem seus sinais de nomes no período escolar, sendo eles, na sua grande maioria, descritivos. Já as crianças surdas, filhas de pais surdos, recebem seus sinais de nomes de seus próprios pais ou amigos surdos, e também são, na sua maioria, descritivos. Essas semelhanças de nomeação, segundo os autores, são diferentes do processo de nomeação descrito por Supalla (1992), o qual identificou que as crianças surdas, filhas de pais surdos, tendem a receber sinais arbitrários. Nesta comunidade os sinais atribuídos às pessoas, na maioria das vezes, não mudam, mesmo se for um sinal descritivo que foi motivado por uma característica pessoal que mais tarde deixou de existir ou se tiver o nome de sinal que for depreciativo ou provocativo. Entretanto, os autores ressaltam que pode ocorrer mudança no sinal de nome de algum sujeito em situações quando há problemas de identificação entre duas pessoas e sinais muito genéricos.

Outro registro importante diz respeito ao período em que os pais surdos nomeiam seus filhos na Língua de Sinais. Tradicionalmente, na comunidade ouvinte grega, uma criança não recebe um nome até a cerimônia de batismo, sendo referida até este momento como "bebê". A comunidade surda segue a mesma tradição, ou seja, só atribui um sinal de nome após o batismo e até este momento usa o termo "bebê" para se referir à criança. Uma divergência apresentada no ato de nomear crianças surdas em comparação com crianças ouvintes gregas, conforme os autores, é que essas últimas muitas vezes recebem nomes para homenagear os avós, e isso não foi possível encontrar no caso de pessoas surdas. A análise do momento no qual ocorre a nomeação é um aspecto importante do estudo antroponomástico dos nomes, conforme se evidencia na última seção deste artigo. 
A pesquisa também aponta que alguns sinais de nomes nesta comunidade podem incluir referências de gênero e referências familiares; e sinais de nomes obtidos após o final da escolaridade podem estar associados a ocupações ou vocações. Essa característica, segundo os autores, pode ser encontrada no processo de nomear pessoas ouvintes na comunidade grega. A carga semântica deste tipo de sinais de nome o faz equiparáveis a certas alcunhas que se tornaram sobrenomes em línguas orais europeias, de acordo com pesquisas antroponomásticas mencionadas na última sessão deste artigo.

Por fim, os autores discutem o contexto educacional das crianças surdas e a relação com o processo de atribuição de sinais de nomes. A Língua de Sinais Grega foi oficializada nos anos 2000 e, a partir deste momento, ela foi inserida no processo educacional das pessoas surdas. A partir disso, os autores afirmam que os intérpretes de língua de sinais começam a sentir necessidade de sinais que nomeiem pessoas históricas e contemporâneas, bem como lugares. Concomitantemente, os surdos começam a ter um conhecimento maior da língua grega escrita e falada. Neste sentido, os autores percebem que mais sinais inicializados estão surgindo (o que não era muito frequente na GSL) e preveem que esse tipo de sinal será mais frequente na atribuição de sinais de nomes, embora não comprovem essa previsão. Nota-se que, no decorrer do artigo, não há nenhuma referência aos estudos onomásticos.

Os pesquisadores chineses Shun-chiu e Jingxian (1989), em seu artigo How Deaf Children in a Chinese School Get Their Name Signs (Como as crianças surdas em uma escola chinesa recebem seus sinais de nome) procuraram traçar o processo de atribuição dos sinais de nomes de crianças surdas recém chegadas à Escola Guangzhou para Surdos, única escola da periferia de Guangzhou. Nesse artigo, os pesquisadores identificam as pessoas que nomearam essas crianças, discutem a natureza desses nomes e analisam a sua estrutura linguística.

Essa pesquisa foi feita com os 21 alunos internos que ingressaram no ano de 1985 , sendo eles 12 meninos e 9 meninas, que viviam alojados em dormitórios masculinos e femininos. Cada dormitório ainda tinha dois alunos mais velhos que atuavam como monitores. Os pesquisadores entrevistaram os pais das crianças, as professoras e os monitores responsáveis pelos quartos. 
As crianças surdas chinesas chegam à escola sem um sinal de nome, o que foi confirmado pelos pais dos alunos, que são ouvintes que desconhecem a língua de sinais; possuindo apenas um nome correspondente na língua oral, que, segundo os autores, não tem significado para esta criança, pois não pode ouvi-lo nem escrevê-lo. As professoras das crianças também não tinham a responsabilidade de atribuir um sinal de nome, mas ensinar aos alunos a ler e a escrever seus nomes oficiais. Por fim, foi detectado que os monitores foram os responsáveis por atribuir os sinais de nome, uma vez que era necessário chamar as crianças três vezes ao dia: para a higiene matinal, na hora do almoço e na hora de dormir.

$\mathrm{O}$ ato de atribuir um sinal de nome seguia um ritual. Eles chamavam o aluno (apontando), falavam da aparência dele (algo que o identificava), mostravam o léxico na Língua de Sinais Chinesa correspondente ao termo "SINAL", apontavam seu novo sinal, que os autores traduziram por "SEU NOME SINALIZADO É ASSIM". Cada um recebeu seu sinal de nome ao mesmo tempo em que foram divulgados para todos os internos, segundo os autores, o procedimento lembra uma cerimônia de batismo realizada quando um padre batiza um bebê. Contudo, como se explica na última seção deste artigo, a nomeação do sinal de nome não é oficial, como é o caso do nome de batismo.

Segundo os autores, os sinais de nomes chineses seguiram uma tradição oral, uma vez que é comum nas escolas primárias chinesas recepcionar visitantes com aplausos seguidos de um “shushu hao, a’yi hao” ('olá, tio; ou olá, tia'), sugerindo uma prática cativante. Assim sendo, dois padrões foram assimilados na atribuição de um sinal “SINAL COM UMA CARACTERÍSTICA PESSOAL + sinal de IRMÃO-MAIS-JOVEM” para os meninos e "sinal de IRMÃ-MAIS-JOVEM + CARACTERÍSTICA PESSOAL" para as meninas. Entretanto, os autores esclarecem que essa foi uma escolha daquela escola e não representa todas as formas de atribuição realizadas em todas as escolas; por exemplo, em uma escola para surdos em Xangai e outra em Fuzhou, província de Fujian, um sinal de nome é composto por um sinal inicial, representando um sobrenome seguido de uma característica pessoal daquele que está sendo nomeado. Em Shaoguan, o sinal para identificar o masculino é usado no lugar de JOVEM-IRMÃO. Diante disso, os autores acreditam que usar os termos IRMÃO-MAIS-JOVEM e IRMÃ-MAIS-JOVEM, são motivados para diferenciar o sexo, bem como para mostrar alguma intimidade. 
No que diz respeito à motivação das escolhas dos sinais de nome, os autores acreditam que, diante da falta de conhecimento sobre os antecedentes e referências familiares, bem como da falta de uma variação na forma de vestir, as características pessoais foram as preferidas. Dos vinte e um sujeitos que receberam o sinal de nome, dezenove receberam sinais de nome localizados no rosto. Apenas dois foram usados de uma outra forma. Uma menina foi "batizada" com um sinal de nome significando “PIANO”, pois a mesma gostava de tocar o instrumento, enquanto outra garota recebeu o sinal “AMARELO”, pois é o que significa a tradução do seu nome.

Os autores discutiram também a atribuição de um sinal de nome motivada por alguma característica que pode trazer certo constrangimento ao nomeado; eles identificaram quatro sinais que foram considerados embaraçosos: LOUCO, PORCO, CHORAR e um sinal apontando para uma mandíbula proeminente. Os pesquisadores acreditam que os sujeitos que receberam esses sinais não conseguiram evitá-los, fazendo uma analogia à forma como os ouvintes recebem seus nomes dos pais: de uma forma imposta. Nas línguas orais, uma palavra tabu é usada com modificações fonológicas, isto é, mudanças fonológicas neutralizam nomes embaraçosos. Este é o caso, por exemplo, da palavra desgraçado a qual por ser considerada tabu, no passado, teve sua pronúncia alterada para “desgranhado”, “disgranido”, “disgramados”, entre outras (GUÉRIOS, 1956, p. 21).

Nas línguas de sinais este fenômeno também ocorre, porém mediante mudanças morfológicas. Os dados analisados pelos autores mostram que os nomes de sinais que apresentam algum significado tabu são alterados menos de um mês após sua criação, alterações que são feitas alterando-se, por exemplo, a localização do sinal ou a configuração da mão (SHUN-CHI; JINGXIAN, 1989, p. 318) e defendem que da mesma forma que acontece com os nomes das línguas orais, onde, nas línguas de sinais, mudanças morfológicas podem causar o mesmo efeito. Ressalte-se também que os apelidos são igualmente impostos, se bem não sejam oficiais, como se explica na última seção deste artigo.

Barros (2018), por fim, propõe uma taxonomia para os sinais de nomes da Língua Brasileira de Sinais com base em informações geradas por 113 entrevistas realizadas no segundo semestre de 2012. Os nomes de sinais coletados foram atribuídos pelos 
professores aos estudantes em ambiente escolar. A geração de dados foi feita por entrevistas gravadas e envolveu educadores e alunos da Universidade Federal de Goiás. A pesquisa se destaca não só por se filiar à Antroponomástica, mas, também, por propor uma taxonomia inédita dos sinais de nome a partir da taxonomia toponímica proposta por Dick (1992).

Contudo, vale ressaltar que, mesmo tendo em vista a homogeneização limitadora da amostra, uma vez que os públicos-alvo são docentes e acadêmicos, todos de um mesmo ambiente educacional, a pesquisadora enfatiza a necessidade de realização de mais pesquisas na área, tendo como aporte dados mais diversificados, objetivando, assim, a verificação da existência de influência de ascendência surda na nomeação.

A análise dos processos de nomeação narrados nas entrevistas respaldou as seguintes taxes propostas por Barros; Aspectos Físicos (AF), Aspectos Comportamentais (AC), Aspecto Social (AS) e Empréstimos de Língua Oral (ELO), os quais abrangem os nomes de sinais arbitrários mencionados por Supalla (1992). Do ponto de vista quantitativo:

A análise dos dados mostrou que apenas 8 dos 113 sinais-nomes pertencem exclusivamente à taxe Empréstimo de Língua Oral (ELO), dados que se opõem à tendência nos Estados Unidos, relatada por Supalla (1992), de a taxe ELO ser amplamente usada sem estar em combinação com as demais taxes. Sinaisnomes que combinam a taxe ELO e alguma outra taxe são 88 do total derı. Assim, todos os sinais-nomes que utilizam a taxe ELO, sozinha ou em combinação com as demais, representam uma maioria de 96 dos 113 sinaisnomes analisados.

Dos sinais-nomes que utilizam a taxe ELO combinada (total de 88), 66 estão combinados à taxe Aspecto Físico (AF), 16 à taxe Aspecto Comportamental (AC), 4 à taxe Aspecto Social (AS) e 2 às taxes $\mathrm{AC}$ e $\mathrm{AF}$ ao mesmo tempo, mostrando uma preferência significativa pela combinação entre as taxes ELO e AF (BARROS, 2018, p.17).

De acordo com a revisão de literatura ora apresentada, estudos referentes aos sinais de nomes já foram pesquisados em várias línguas de sinais ao redor do mundo. No recorte que apresentamos, podemos identificar que esses processos possuem pontos em comum, bem como divergências. Uma questão que pode ser inferida das pesquisas reunidas neste artigo para se compreender as questões mais convergentes, diz respeito a algo que praticamente todas as comunidades surdas experimentam: são comunidades linguísticas que coexistem com comunidades linguísticas majoritárias. Todos os artigos 
apresentaram o fato de que as crianças surdas, na grande maioria, quando filhas de pais ouvintes, chegam à escola sem portar um sinal de nome correspondente na Língua de Sinais.

No que diz respeito às divergências apresentadas, como a forma como os pais surdos atribuem sinais aos seus filhos ou até mesmo na forma de diferenciar nomes de sinais masculinos e femininos, como acontece na Língua de Sinais Sueca, pode-se afirmar que, apesar de todas serem comunidades de surdos usuários de língua de sinais, elas se organizam dentro de um contexto sócio-histórico-cultural próprios, em que as línguas de sinais são constituídas e os sinais de nomes refletem essa organização.

As pesquisas aqui apresentadas vêm confirmar o que já foi dito anteriormente: o hábito de dar nomes às pessoas reflete aspectos culturais de uma sociedade. Um nome próprio pode registrar atitudes e posturas sociais de um determinado grupo, bem como crenças, profissões, regiões de origem, dentre outros aspectos (CARVALINHOS, 2007). Neste sentido, acreditamos que pesquisas voltadas à compreensão do processo de nomear pessoas surdas podem contribuir com as pesquisas no campo da Onomástica de uma forma geral.

Considerando que os estudos Onomásticos não foram identificados na maioria dessas pesquisas, a última seção deste artigo, reanalisa alguns dos resultados obtidos pelos pesquisadores de Libras de modo a mostrar algumas contribuições da utilização dos paradigmas em vigor na Antroponomástica para o estudo da nomeação de pessoas em comunidades surdas.

\section{Avaliação das pesquisas sobre os nomes nas línguas de sinais de acordo com a Antroponomástica}

Borstell (2017) inseriu, nas palavras-chave, termos relativos à Antroponomástica. Não obstante, não ter destinado nenhuma sessão à temática, do ponto de vista metodológico, sua pesquisa se equipara às realizadas no âmbito da Socioonomástica. Kourbertis e Hoffmeister (2002), por sua vez, trazem uma análise mais detalhada baseada nos diferentes tipos de nomes, o que evidencia, por parte dos pesquisadores, certo domínio da categorização de nomes postulada pela Antropomástica. Mesmo a 
distinção entre nomes de sinal arbitrários e nomes de sinal descritivos proposta por Supalla (1990) pode ser aprofundada pela inclusão dos achados na área.

Uma característica recorrente das pesquisas sobre os nomes de sinais descritas nesta revisão de literatura refere-se ao fato de a pessoa nomeada receber um nome de sinal a partir do momento em que é introduzida à comunidade surda, introdução que, na maioria das vezes, é concomitante à entrada da criança no sistema de educação formal. No caso de pessoas adultas a quem é atribuído um sinal, isto ocorre quando ela passa a interagir com pessoas surdas, interação que as fazem participar da comunidade surda. Outra circunstância que motiva a atribuição de sinal de nomes a pessoas é a necessidade de se fazer referência a ela no discurso, o que costuma ser o caso quando há a necessidade de se referir a celebridades ou a personagens históricas, por exemplo.

Uma análise mais detida deste aspecto da nomeação pode ser alcançada quando se leva em consideração a categorização dos processos nominativos proposta por Van Langendonck (2007). Explica o especialista em Antroponomástica que os nomes oficiais são dados oficialmente pelo estado ou por instituições religiosas. Em contrapartida, os nomes não oficiais podem ser dados por qualquer pessoa. Os chamados nomes primários são aqueles que apresentam as seguintes funções: são usados para se dirigir a alguém (isto é, permite que se converse com alguém), para identificar alguém (que permite que se fale sobre alguém). Os nomes secundários, por sua vez, são do ponto de vista cronológico ou funcional, posteriores aos nomes primários (VAN LANGENDONCK, 2007, p. 189). Assim, do sistema binário proposto, surgem as seguintes possibilidades de categorização: nome oficial primário, nome oficial secundário, nome não oficial primário e nome não oficial secundário.

Considerando a obrigatoriedade legal de se nomear as crianças e de registrá-las em cartórios na língua oficial majoritária de cada país, entende-se que os nomes de sinais são não oficiais com relação aos nomes oficiais das línguas orais, se bem, no interior da comunidade surda, o nome de sinal possa exercer todas as funções descritas para os nomes primários, havendo, portanto, para além do caráter legal do nome oficial, apenas uma diferença cronológica decorrente de o nome de sinal ser atribuído depois do registro do nome civil das crianças surdas. Desnecessário dizer que, para os adultos 
ouvintes que recebem nomes de sinal quando ingressam ou são aceitos na comunidade surda, o nome de sinal também é secundário em relação ao nome civil.

A distinção entre nome oficial e nome não oficial também é utilizada por Amaral (2011) em sua análise de tipos de nomes na antroponímia da Língua Portuguesa do Brasil: para esse pesquisador, os nomes oficiais que fazem parte do nome civil são prototípicos e pertencem à categoria dos ortônimos, já os nomes não oficias fazem parte da categoria dos alônimos. Estão incluídos nesta última categoria seis tipos de nomes: hipocorísticos, apelido, pseudônimo, heterônimo, nome artístico (inclui o nome de palco) e o nome de guerra (AMARAL, 2011, p. 76). Destas categorias interessam mais de perto às pesquisas atuais sobre a nomeação nas comunidades surdas, as categorias dos hipocorísticos e dos apelidos.

Tanto hipocorísticos quanto apelidos são secundários e atribuídos ao portador, porém há uma diferença ente eles: morfologicamente, os primeiros são formas derivadas dos prenomes oficiais, derivação que pode dar-se por sufixação, aglutinação ou abreviação. No que se refere à semântica, ambos podem ter conotação pejorativa ou melhorativa ou carinhosa, porém, os apelidos que não são hipocorísticos, são chamados de alcunha. Diferentemente dos hipocorísticos, as alcunhas se caracterizam por fazerem menção a alguma qualidade do nomeado. Estariam, nesta categoria, os nomes descritivos da categorização de Supalla (1990).

Todos os nomes de sinais classificados como não arbitrários por Supalla (1992) compartilham com as alcunhas o fato de procurarem descrever um traço do nomeado socialmente avaliado como relevante. Como bem lembraram Kourbertis e Hoffmesteir (2002), muitas alcunhas deram origens, na língua grega, a sobrenomes ao serem herdados de pai para filho. Esta evolução de alcunha para sobrenomes se verifica em outras línguas modernas europeias, com inclusão da língua portuguesa. Não parece provável que o mesmo se dê nas comunidades surdas. Primeiro, por elas serem pequenas, raramente há necessidade de distinção de nomes homônimos, segundo por não ser necessária a criação de sobrenomes (como foi o caso das línguas europeias a partir do fim da idade média), uma vez que todos os membros já portam um nome civil completo constituído por nome e sobrenome. 
Em sua pesquisa sobre a língua de sinais americana, Supalla (1990) considerou como arbitrários os nomes cuja configuração de mão representavam a letra inicial do nome, seja ele o prenome, o sobrenome ou o apelido inglês. De acordo com os estudos antroponímicos, esta abreviação ou encurtamento do nome civil produz uma forma hipocorística do nome, ou seja, um hipocorístico, "um item formado a partir de uma alteração morfológica (...) de outro antropônimo” (AMARAL, 2011, p. 92). Assim, os nomes registrados e analisados por Supalla (1990) são nomes que abreviam o nome civil retendo, apenas a letra inicial, sendo assim, eles podem ser considerados como verdadeiros hipocorísticos, se bem que, em outras línguas de sinais, como a Libras, conforme Barros (2018), os nomes de sinais arbitrários são recursos com os quais o empréstimo linguístico se combina com outros, formando os nomes híbridos.

Outro aspecto que merece ser explorado com mais profundidade diz respeito à existência de várias nomeações secundárias nas comunidades surdas. Na língua grega de sinais, Kourbertis e Hoffmesteir (2002) mencionam casos nos quais um sujeito recebe diferentes sinais de nome e desvelam a existência de alcunhas que transcendem o nome de sinal de batismo na comunidade surda e ainda formas de chamamento provocativo usadas de forma sigilosa, de modo que o assim nomeado pode nunca saber como é chamado, maliciosamente, por seus pares na comunidade surda. Nestes casos, pode-se considerar os sinais de nome como primários, em relação aos quais as alcunhas dadas posteriormente, bem como as formas alternantes de chamamento são secundárias. Não se sabe, contudo, em que medida há estes tipos variados de chamamento em outras comunidades surdas usuárias de outras línguas de sinais. A existência deste tipo de funcionamento dos nomes de sinais, usados exclusivamente para se falar de alguém e não para dirigir-se a alguém, aponta para a necessidade de criação de novas categorias de nomes na Antroponomástica.

\section{Considerações finais}

As reflexões trazidas neste artigo procuraram evidenciar alguns aspectos que podem ser aprofundados em pesquisas posteriores mediante a adoção dos paradigmas 
de pesquisa da Antroponomástica cuja contribuição pode abrir novas perspectivas de pesquisa na área da nomeação em comunidades surdas. Além disso, ressalte-se que também é promissora a adoção de um viés comparado no estudo da nomeação nas línguas de sinais em que se comparam resultados já obtidos para as antroponímias de línguas orais com aquelas próprias das comunidades surdas.

\section{Referências}

AMARAL, Eduardo Tadeu Roque. Contribuições para uma tipologia de antropônimos do português brasileiro. Alfa, São Paulo, 55(1), p. 62-82, 2011.

BARROS, Mariângela Estelita. Taxonomia Antroponímica nas Línguas de Sinais: A motivação dos Sinais-nomes. RE-UNIR, Rondônia, v.5. no 2, p. 40-62, 2018.

BÖRSTELL, Carl. Types and trends of name signs in the Swedish Sign Language Community. SKY Journal of Linguistics, 30, p. 7-34, 2017.

CARVALINHOS, Patrícia de Jesus. As origens dos nomes de pessoas. Domínios de Lingu@gem, Uberlândia, ano 1, n.1, 2007.

DAY, Linda. \& SUTTON-SPENCE, Rachel. British sign name customs. Sign Language Studies 11, (1), p.22-54, 2010.

Desrosiers, J and C. Dubuisson. Names in Quebec Sign Language and What They Tell Us about Quebec Deaf Culture. In Perspectives on Sign Language Usage: Papers from the Fifth International Symposium on Sign Language Research, vol. 2, ed. I. Ahlgren, B. Bergman, and M. Brennan,249-6o. Durham: The International Sign Linguistics Association, 1994.

DICK, Maria Vicentina de Paula do Amaral. Toponímia e Antroponímia no Brasil. Coletânea de Estudos. 2. ed. FFLCH: São Paulo, 1992.

FRAI, Patrícia Helena. Sócio-onomástica: uma nova abordagem metodológica. ENTRELETRAS, Araguaína, v.7, n.1, jan./jun. 2016.

GUÉRIOS, Rosário Farani Mansur. Tabus linguísticos.2ª.ed. Rio de Janeiro: Organizações Simões, 1956. 
HEDBERG, Tomas. Persontecken: Deras härkomst, bildningssätt och användning [Name signs: Their origin, formation, and use. Forskning on teckenspråk (FoT) XVI, Department of Linguistics, Stockholm University, 1989.

Name signs in Swedish Sign Language: Their formation and use. In Erting, Carol J. \& Johnson, Robert C. \& Smith, Dorothy L. \& Snider, Bruce D. (eds.), The Deaf Way: Perspectives from the International Conference on Deaf Culture, 416-424. Washington, DC: Gallaudet University Press, 1994.

KOURBETIS, Vassilis. \& HOFFMEISTER, J. Robert. (2002). Name signs in Greek Sign Language. American Annals of the Deaf. 147 (3), 35-43.

LÓPEZ FRANCO, Yolanda Guillermina. Los nombres de pila en la década de 1980 en Montpellier, Francia, y em Tlalnepantla de Baz, México, bajo un enfoque socioantroponímico. In: Ciências do Léxico. Lexicologia, Lexicografia, Terminologia. ISQUERDO, Aparecida Negri; DAL CORNO, Giselle Olivia Mantovani (orgs.). vol.VII.Campo Grande,MS: Editora UFMS, 2014, p.15-38.

MCKEE, Rachel Locker; MCKEE, David. Name signs and identity in Deaf communities in New Zealand Sign Language. In: M. Metzger (ed.) Bilingualism and Identity in Deaf Communities. Washington: Gallaudet University Press, 200o, p. 3-40.

MINDESS, A. What name signs can tell us about Deaf culture. Sign Language Studies, 66, p. 1-23, 1990.

PAALES, Liina. On the system of person-denoting signs in Estonian Sign Language. Sign Language Studies 10 (3). Washington: Gallaudet University Press, 2010, p. 317-335.

SEABRA, Maria Cândida Trindade Costa de; ISQUERDO, Aparecida Negri. A onomástica em diferentes perspectivas: resultados de pesquisas. Revista de Estudos da Linguagem, v. 26, n.3, p. 993-1000, 2018.

SEIDE, Márcia Sipavicius. A identidade religiosa na antroponímia de Marechal Cândido Rondon. Relin, Belo Horizonte, v.24, n1, 2016.

SILVA, Terezinha Baldez e.; MORAES, Pedro Henrique de. A nomeação dos topônimos: memória e história em confronto entre o passado e o presente. Littera Online. São Luis, n. 10, 2015 .

SUPALLA, Samuel J. (1990). The arbitrary name sign system in American Sign Language. Sign Language Studies, 1990, 67, p. 99-126. 
. The Book of Sign Names. Berkeley: DawnSignPress. 1992.

TROPRAKSOY, Abdullah Linguistic study on the system of personal name signs in Turkish Sign Language (TSL). Dissertação (Mestrado em Ciências Sociais), Hacettepe University Graduate , Ankara, 2015.

VAN LANGENDONCK,Willy. Theory and typology of proper names. Berlin: Walter de Gruyer, 2007.

YAU, Shun-chiu. \& HE, Jingxian. How Deaf children in a Chinese school get their sign names. Sign Language Studies, 1989, 18(65), p. 305-322.

Recebido em 03/02/2020.

Aprovado em 20/05/2020. 